\title{
Load velocity influence on changes of soil consolidation and permeability parameters in CL-type tests
}

\author{
Paweł DOBAK ${ }^{1}$, Tomasz SZCZEPAŃSKI ${ }^{1, *}$ and Sebastian KOWALCZYK ${ }^{1}$ \\ 1 University of Warsaw, Faculty of Geology, Żwirki i Wigury 93, 02-089 Warszawa, Poland
}

Dobak, P., Sczepański, T., Kowalczyk, S., 2015. Load velocity influence on changes of soil consolidation and permeability parameters in CL-type tests. Geological Quarterly, 59 (2): 382-390, doi: 10.7306/gq.1178

\begin{abstract}
Obtaining the reliable values of filtration-consolidation parameters depends on appropriate programming of load velocity. The paper presents a critical assessment of the criteria for selecting the load velocity with regard to a theoretical model of consolidation under the constant rate of load (CRL). A key element of interpretation is to distinguish three stages of investigation: mobilization of pore pressure, steady phase and unsteady phase. Reliable values of filtration-consolidation parameters are obtained during the steady phase determined on the basis of dimensionless test parameters, standardized for CRL: the pore pressure and relative time of consolidation $\mathrm{CL}$ (continuous loading). In order to assess the trends in changes of filtration-consolidation properties of the Krakowiec Formation, clays were chosen for investigations. The tests were performed on undisturbed samples and using Middle Miocene soil pastes at different load velocities to propose a method to choose appropriate test speed in CL tests.
\end{abstract}

Key words: consolidation, load velocity, Krakowiec Formation clays, filtration coefficient.

\section{INTRODUCTION}

Tests performed with a continuous load increase are important in the development of uniaxial consolidation tests methodology that refers to solutions of the classical Terzaghi theory, but demands change of approach in interpretation - both in a theoretical and practical aspect. As much faster and resulting with more significant parameters obtained, the CL tests shall be conducted more commonly in any consolidation-related designs. The main general objective of the work is to provide more data for understanding of CL tests, and thus to help with further practical development of procedures and interpretation.

To set the definition frame, acronyms used in the paper are explained here: IL - incremental loading, referred to as STD (standard) as well, CL - continuous loading - general name for the following types of tests: CRL - constant rate of load, CRS constant rate of strain, CG - constant pore pressure gradient.

\footnotetext{
* Corresponding author, e-mail: tom@uw.edu.pl
}

Received: December 17, 2013; accepted April 15, 2014; first published online: July 16, 2014

\section{CONSOLIDATION MODEL UNDER CONTINUOUS CL LOAD INCREASE}

CL tests can be performed with constant velocities preservation of: load CRL (Aboshi et al., 1970), deformation CRS (Wissa et al., 1971), or pore pressure CG (Lowe et al., 1969).

Together with introduction of the described methods, CL tests phases were determined (Wissa et al., 1971; Vu Cao Minh, 1977) as non-steady and steady. Further theoretical studies allowed to standardize the model of pore water pressure changes in the course of CL tests (Dobak, 1995, 1999, 2008), through introduction of non-dimensional quantities:

- pore water pressure parameter $C_{C L}$ :

$$
C_{C L}=\frac{u_{b}}{\sigma}
$$

where: $u_{b}-$ pore water pressure at the base of consolidometer [kPa]; $\sigma-$ applied external stress [kPa],

- relative consolidation time $T_{C L}$ :

$$
T_{C L}=\frac{t}{t_{(T=1)}}=\frac{t \cdot c_{v}}{H^{2}}
$$


Recommended values of $C_{C L}=u_{b} / \sigma$ for various soil types (after Lee et al.,1993)

\begin{tabular}{|l|c|c|}
\hline \multicolumn{1}{|c|}{$C_{C L}=u_{b} / \sigma$} & Soil type & Published by \\
\hline 0.5 & kaolinites, Ca-montmorillonites, Massena clay & Smith and Wahls (1969) \\
\hline 0.05 & Boston blue clay (sedimented artificially) & Wissa et al. (1971) \\
\hline $0.1-0.15$ & Bakebol Clay & Sallfors (1975) \\
\hline $\begin{array}{l}0.3-0.5 \\
\left(u_{b}=7 \mathrm{kPa}\right)\end{array}$ & tills and clays from Coal Basin in the Mississippi Plain (Kentucky) & Gorman et al. (1978) \\
\hline
\end{tabular}

where: $t$ - time from beginning of CRL test $[\mathrm{s}] ; t_{(T=1)}-$ specific time of consolidation [s]; $c_{v}-$ coefficient of vertical consolidation $\left[\mathrm{m}^{2} / \mathrm{s}\right] ; H$ length of drainage path [m].

The $T_{C L}$ parameter can be considered in the $C L$ tests as a measure of advancement of the consolidation process, and is equivalent to consolidation degree $U$.

\section{CRITERIA OF CONSOLIDATION TEST SPEED, LED WITH CONSTANT LOAD VELOCITY}

$C_{C L}$ parameter describes the role of pore water pressure in the course of consolidation and filtration factor, and agreement of test results with application of the Terzaghi theory.

As presented above (Table 1), the proposed quantitative criteria significantly differ, which results from different methodic approaches. Smith and Wahls (1969), on the basis of laboratory testing, allow for high values of $u_{b} / \sigma$ ratio in the course of test. The proposed solutions refer rather to the classical Terzaghi theory. In turn, Wissa et al. (1971), on the basis of the Davis and Raymond (1965) non-linear theory (1965), state that transition from unsteady to steady phase is independent of load velocity.

Experimental works led and described by Gorman et al. (1978) present different criteria of load velocity application. Wide program of comparative research involved CG, CRS, STD IL, tests with use of "back pressure" technique among others, his suggestions was the performance of the tests for soils of $w_{L}>60 \%$, with $\Delta \varepsilon / \Delta$ t speed of $8 \times 10^{-5} / \mathrm{s}$, whereas for lower liquidity index, this speed can be doubled.

On the basis of research results, Lee et al. (1993) proposed a criterion of non-dimensional deformation rate $\beta$, which, referring to the above-mentioned (Dobak, 1999, 2008) specific consolidation time $t_{(T=1)}$ parameter, can be described as:

$$
\beta=\frac{\Delta \varepsilon}{\Delta t} \cdot \frac{H^{2}}{C_{v}}=\varepsilon \cdot t_{(T=1)}
$$

where: $\varepsilon$ - relative strain [-], other explanations as in equations [2].

The presented review indicates lack of conformity and, often, arbitral character of proposed speed test criteria. By this, two important remarks have to be stated:

- the postulate of expected conformity between parameters obtained from IL and CL tests is still to discuss, as in its background lies the unstated condition that the consolidation process in cases of two different soil loading systems is identical;

- consolidation parameters do not have exclusively physical character, though are derived on the basis of certain theory.

Therefore, comparison of parameters obtained from different methods demands prior conformity assessment of soil reaction with the implications of assumed theory.
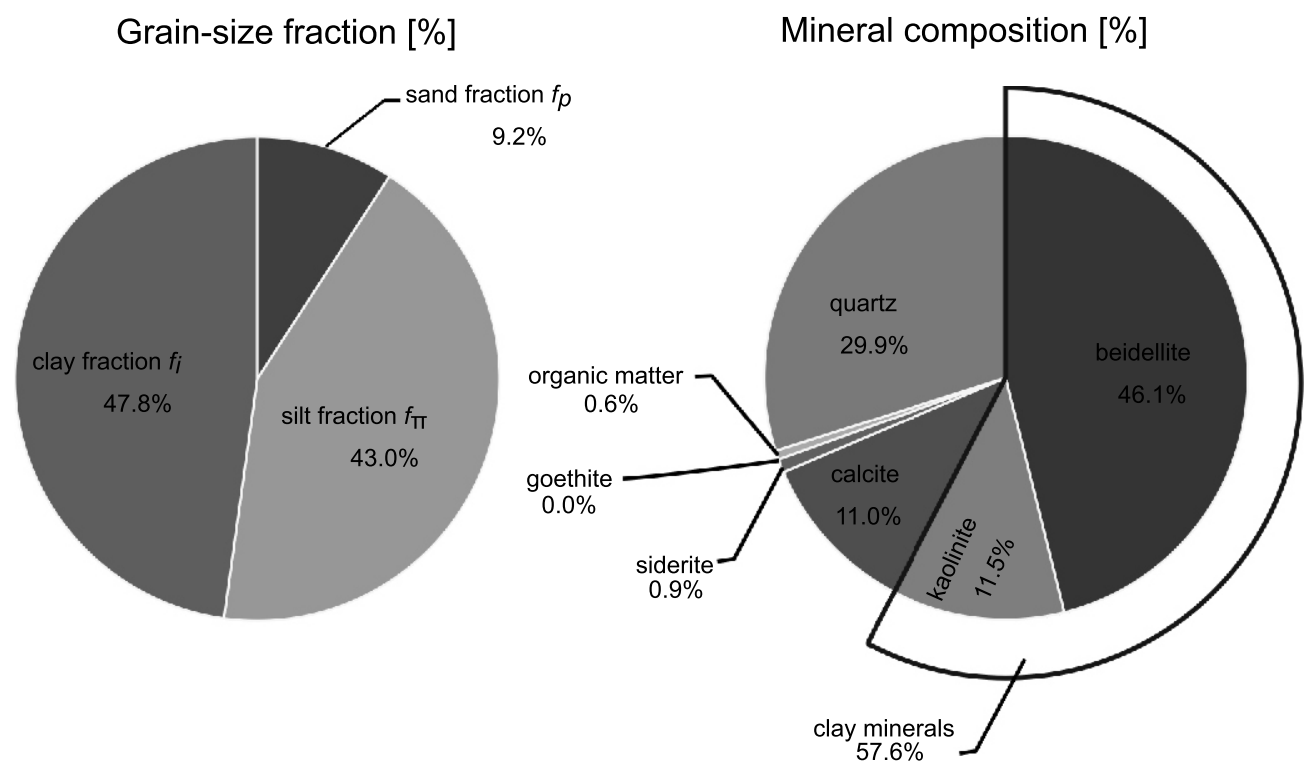

Fig. 1. Granular and mineral characteristic of tested Krakowiec Clay 


\section{METHODOLOGY}

\section{ASSUMPTIONS FOR RESEARCH PROGRAM}

Results of tests led in Rowe and Barden consolidometer on samples of Miocene clays from the Carpathian Depression are presented.

The grain and mineral compositions of tested soils are presented in Figure 1, physical parameters in Table 2.

The Atterberg's limits are as follows: density of solid particles $\rho_{s}=2.72 \mathrm{~g} / \mathrm{cm}^{3}$, plastic limit $w_{p}=24.6 \%$, liquid limit $w_{L}=$ $65.0 \%$

The research program involved comparison of consolidation progress during tests led in 3 load velocities: 25,50 and $100 \mathrm{kPa} / \mathrm{h}$. To determine the influence of the drainage path length, two sample heights: 19 and $32 \mathrm{~mm}$, have been used. Assessment of the role of structural and moisture factors was possible by comparing test results led on undisturbed structure samples, as well as soil pastes.

\section{TEST RESULTS}

\author{
PORE PRESSURE PARAMETERS
}

Consolidation progress analysis in condition of continuous load increase reveals that the experimental measurement results are to a great extent coherent with the theoretical (Dobak, $1999,2008)$ characteristics of non-dimensional $C_{C L}-T_{C L}$ dependence (Fig. 2).

It is also expressed by a discrepancy in the patterns of $C_{C L}-\sigma$ experimental curves with the model solution (Fig. 2), where, according to the classical Terzaghi assumptions, it is expected that immediate and complete stress transfer by pore water $\left(C_{C L}=1\right)$ occurs together with load application. In tested soils (undisturbed and pastes alike), despite of saturation with the use of back-pressure technique, this immediate reaction is not observed, and from the beginning of the test, the soil frame transfers more stresses, than Kelvin's rheological model assumes. As an effect, initial stage of $C_{C L}$ value mobilization is ob-

Table 2

Characteristics of samples tested at different velocity in Rowe and Barden consolidometer

\begin{tabular}{|c|c|c|c|c|c|c|}
\hline $\begin{array}{l}\text { Symbol of } \\
\text { sample }\end{array}$ & $\begin{array}{l}\text { Graphical } \\
\text { marks }\end{array}$ & Structure & $\begin{array}{c}\text { Initial height } \\
\text { of sample } \\
\text { [mm] }\end{array}$ & $\begin{array}{l}\text { Rate of } \\
\text { stress } \\
{[\mathrm{kPa} / \mathrm{h}]}\end{array}$ & $\begin{array}{c}\text { Bulk density } \\
\text { of soil } \rho \\
{\left[\mathrm{Mg} / \mathrm{m}^{3}\right]}\end{array}$ & $\begin{array}{c}\text { Moisture } \\
\text { content } \\
\text { [\%] }\end{array}$ \\
\hline $1-19-25$ & - & \multirow{6}{*}{$\begin{array}{l}\text { natural } \\
\text { structure }\end{array}$} & 19 & 25 & 2.04 & 25.6 \\
\hline $2-32-25$ & $\bullet$ & & 32 & 25 & 2.12 & 20.7 \\
\hline $3-19-50$ & - & & 19 & 50 & 2.07 & 18.1 \\
\hline $4-32-50$ & $\Delta$ & & 32 & 50 & 2.07 & 20.9 \\
\hline $5-19-100$ & ㅁ & & 19 & 50 & 2.05 & 25.8 \\
\hline $6-32-100$ & 0 & & 32 & 100 & 2.06 & 23.9 \\
\hline $7-19-25$ & $\bullet$ & \multirow{5}{*}{$\begin{array}{l}\text { soil- } \\
\text { paste }\end{array}$} & 19 & 25 & 1.79 & 40.1 \\
\hline $9-19-50$ & $\square$ & & 19 & 50 & 1.78 & 38.2 \\
\hline $10-32-50$ & $\Delta$ & & 32 & 50 & 1.81 & 38.5 \\
\hline $11-19-100$ & ם & & 19 & 100 & 1.79 & 40.1 \\
\hline $12-32-100$ & 0 & & 32 & 100 & 1.83 & 40.1 \\
\hline
\end{tabular}
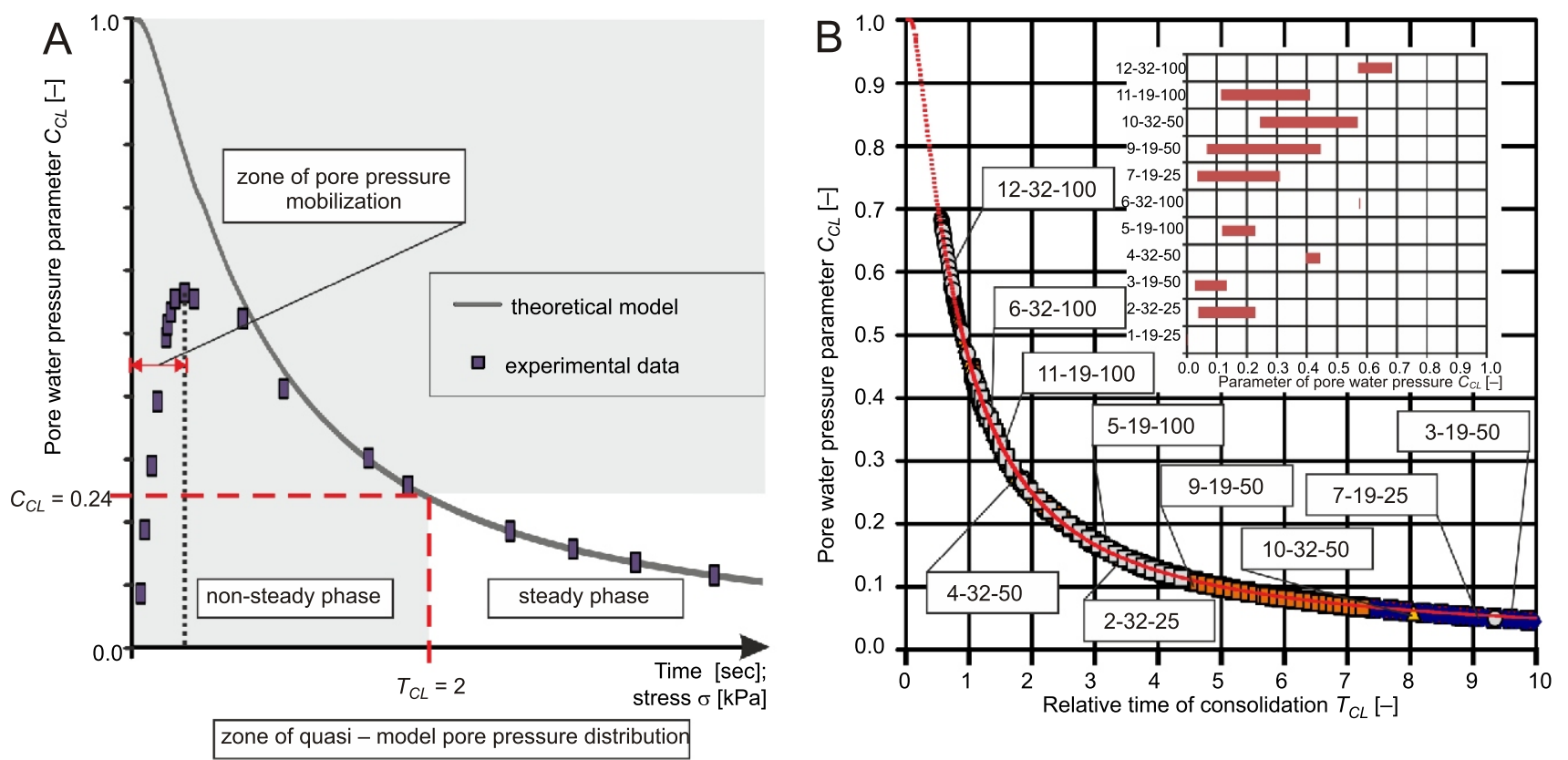

Fig. 2A - phases of CL consolidation test; B - ranges of pore pressure parameter experimental values on the background of theoretical $\mathrm{C}_{\mathrm{CL}}-\mathrm{T}_{\mathrm{CL}}$ dependence 
A
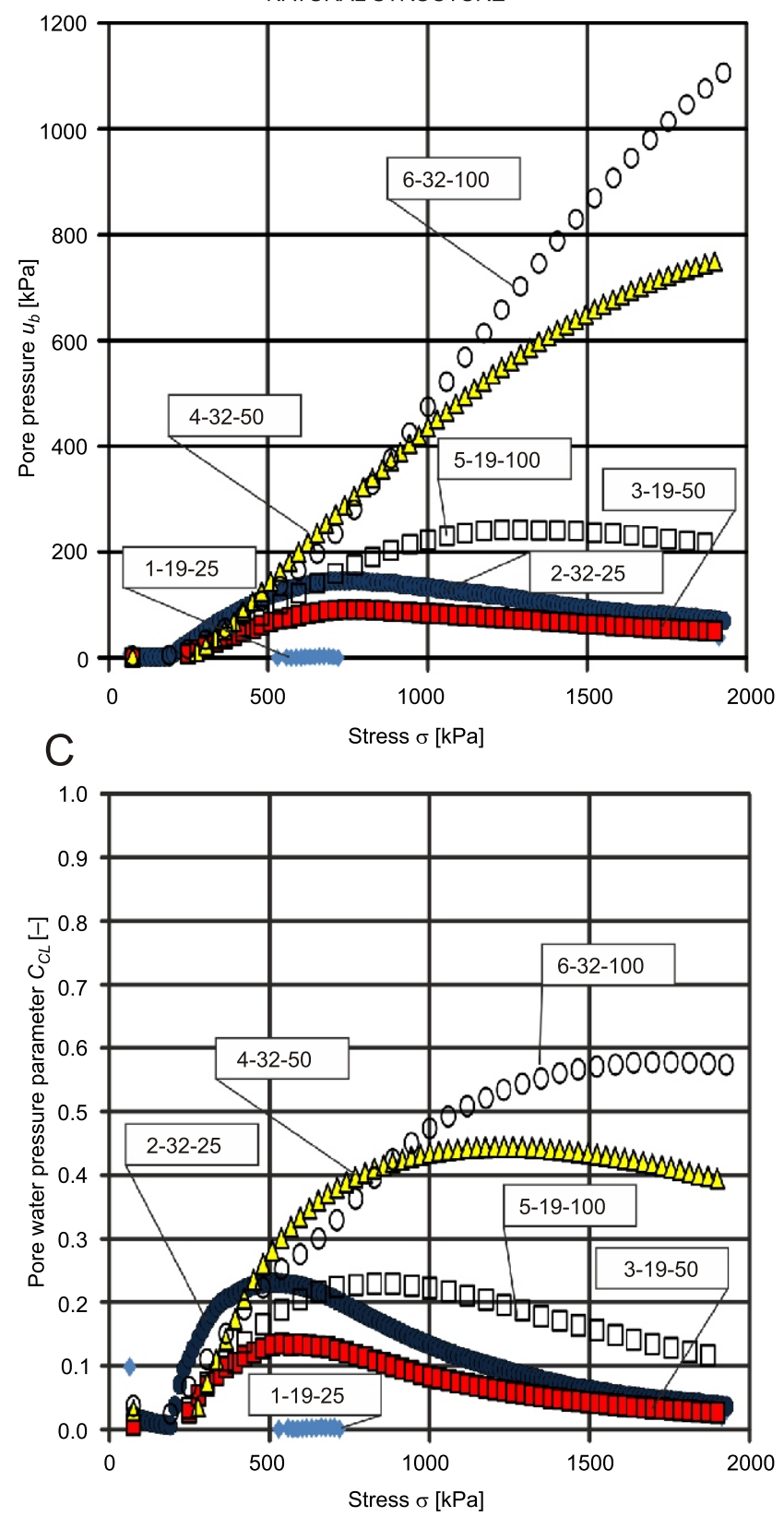

B
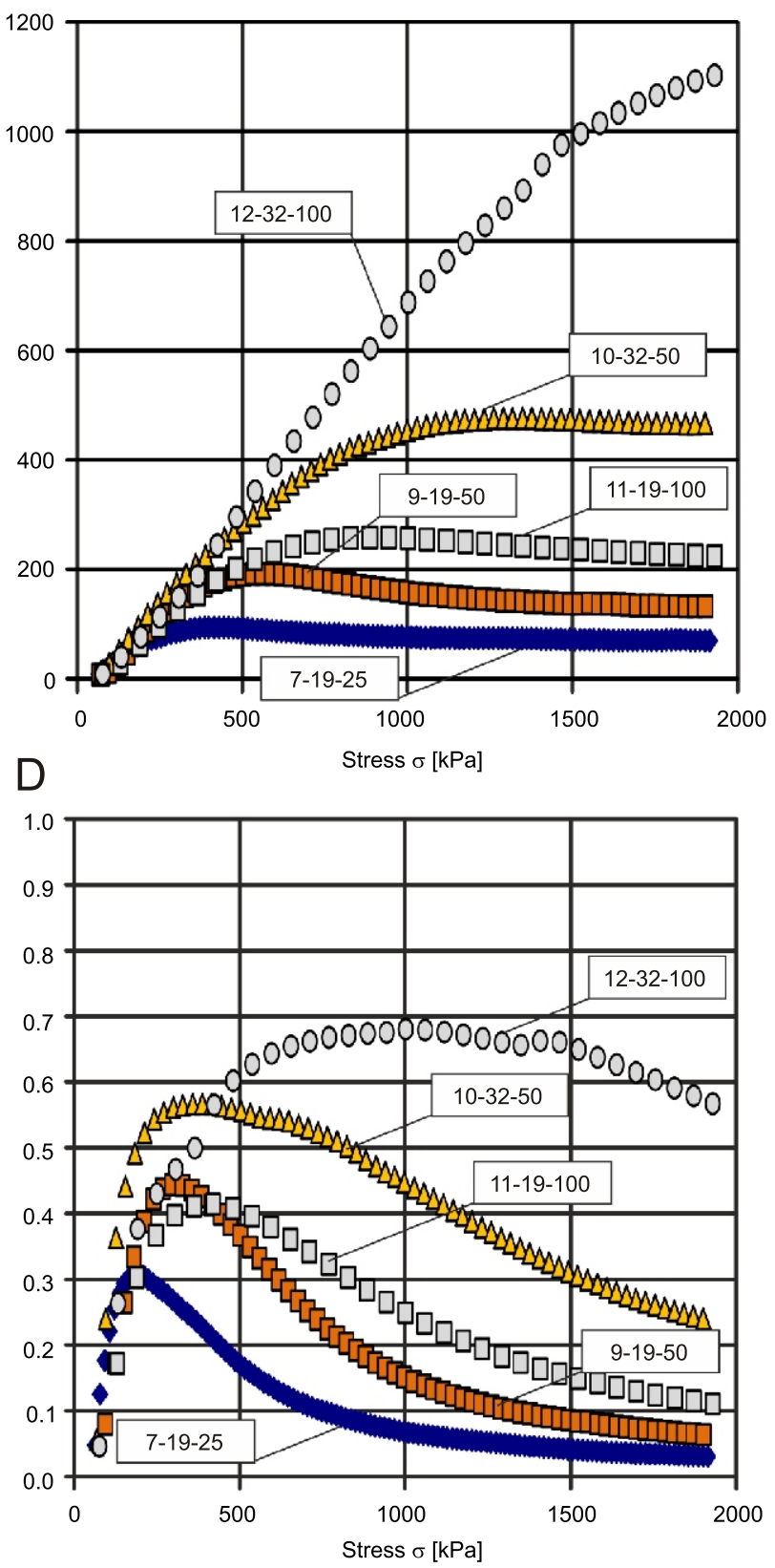

Fig. 3. Pore pressure (A - natural structure, B - soil-paste) and pore water pressure parameter (C - natural structure, D - soil-paste) changes during CL tests at different velocity of loading

served, then reaching $C_{C L \max }$ (usually lower than 1), and finally pore pressure dissipation qualitatively coherent with the model process occurs.

The $C_{C L}$ mobilization stage demands separate theoretical description and shall not be considered in determination of reliable consolidation and permeability coefficients without application of special interpretational solutions. Whereas, starting from reaching $C_{C L \max }$, conditions of unsteady and steady phases occurrence shall be considered and further consolidation parameters shall be analysed with relation to them. This requirement is important both in incremental mode of loading (Woźniak, 2009) and in continuous loading tests (Kowalczyk, 2005; Dobak and Kowalczyk, 2008)

Results of the performed tests illustrate the following tendencies (Fig. 3):
- increase of pore pressure $u_{b}$ is observed both in pastes and undisturbed structure soils. Initially, it proceeds similarly, independently from test speed, and even from the drainage length (sample height). Although, this increase expires according to model theoretical assumptions (Dobak, 2008), even revealing further slight fall. It could point to the improvement of drainage conditions during the test, which is confirmed by a correlated decrease of the specific consolidation time $t_{(T=1)}$ parameter;

- in the tests performed with higher load velocity, values $u_{b \max }$ are higher and reached later. This trend is generally coherent with theoretical assumptions, however, accordingly to the model (Dobak, 1999), the expected proportional nature of $u_{b \max }$ value to the test speed $\Delta \sigma / \Delta t$, is not observed. Instead, from the analysed measure- 
A

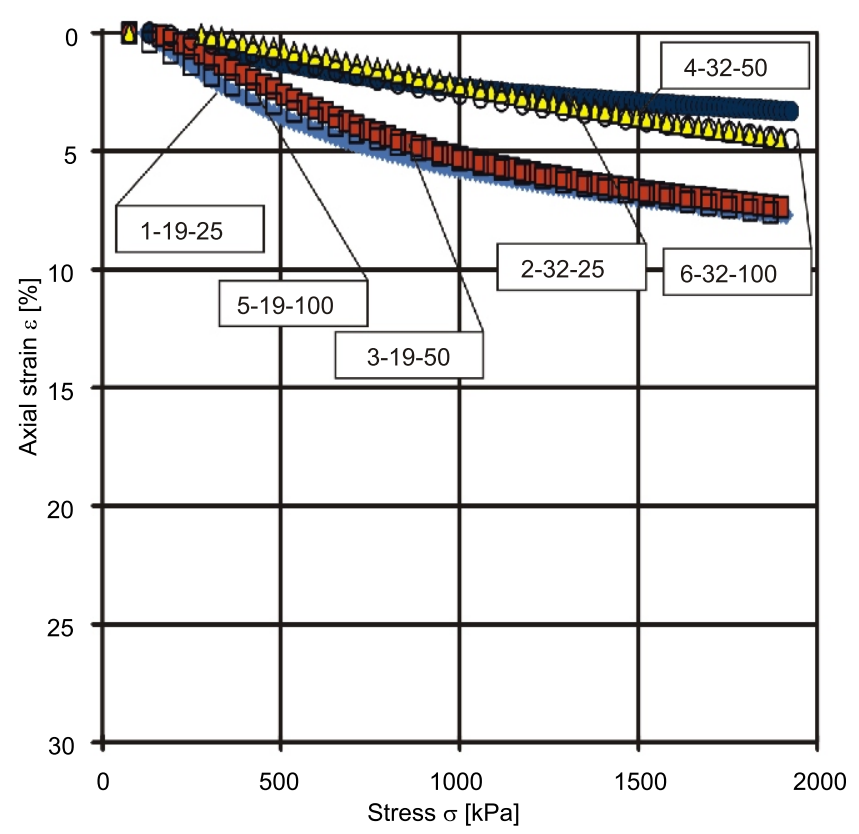

C

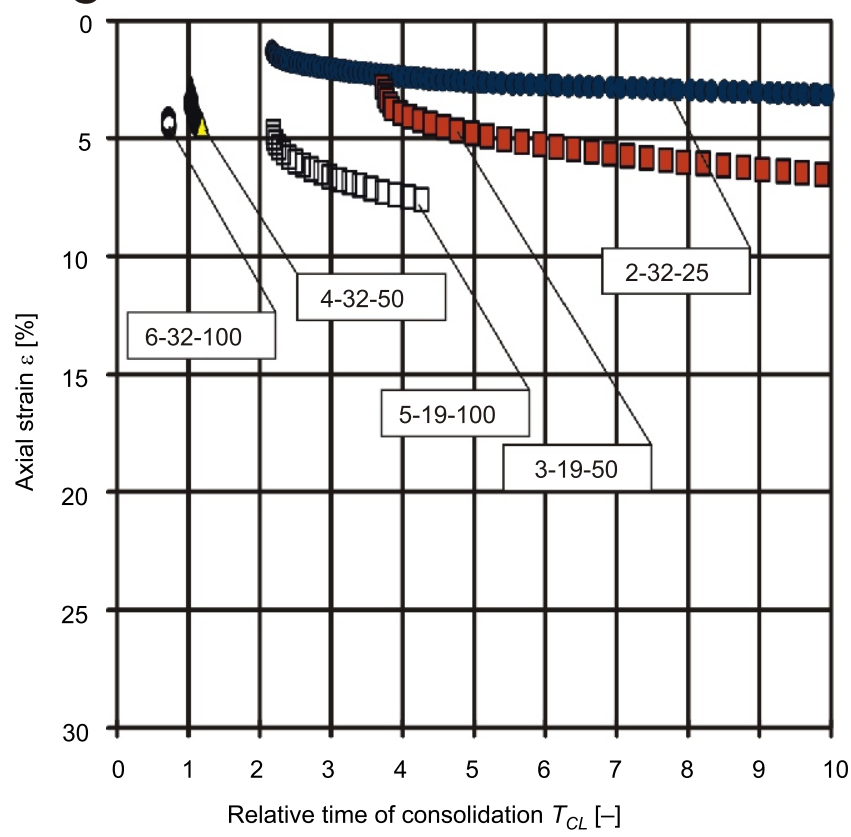

B

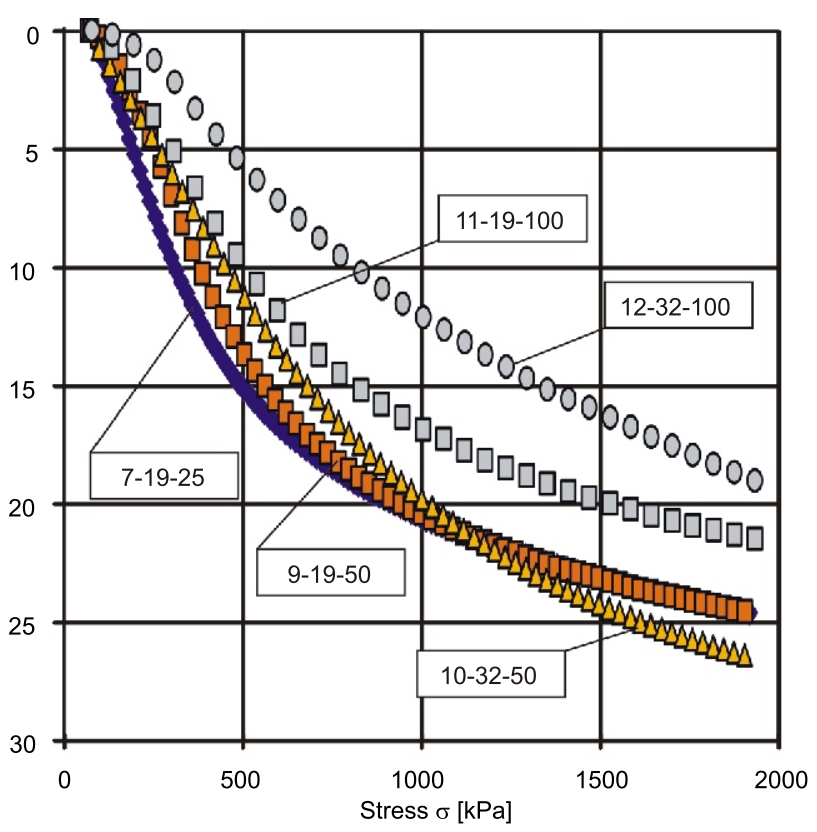

$\mathrm{D}$

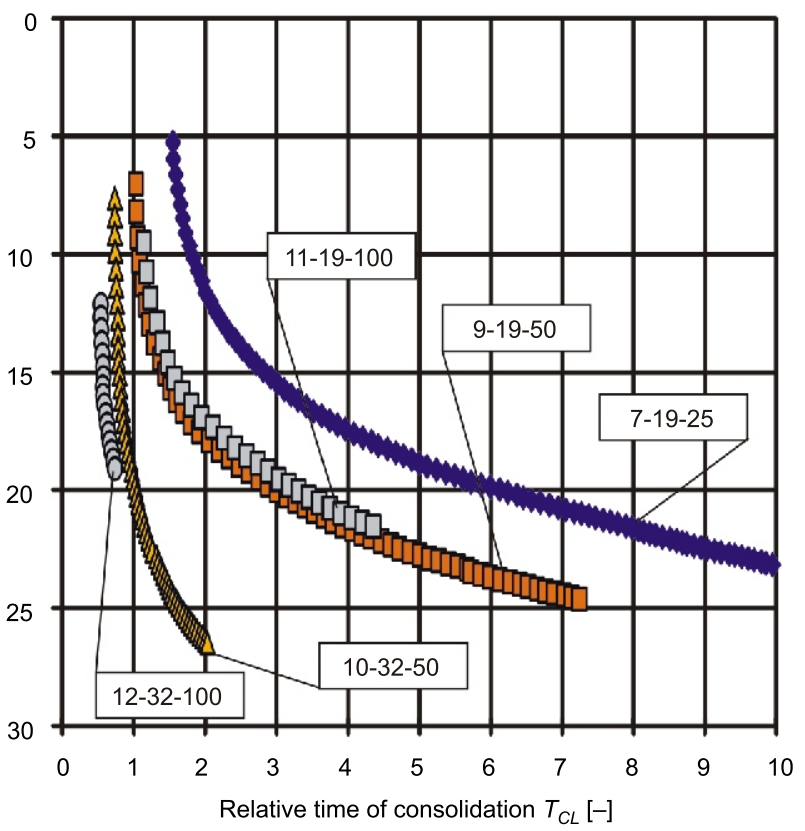

Fig. 4. Dependence between strain vs. stress ( - natural structure, $B$ - soil-paste) and relative time of consolidation (C - natural structure, D - soil-paste)

ments, it rather appears that application of higher $\Delta \sigma / \Delta t$ velocities is continuously less reflected in generating higher pore pressures;

- contribution of liquid phase to load transfer changes in the course of CL consolidation and depends both from load velocity and structural factors. As an example, in the performed tests, it was observed that $C_{C L \max }$ values are higher in pastes than in undisturbed structure soils.

\section{AXIAL DEFORMATIONS}

Changes of relative axial deformation $\varepsilon$ for soils of various structures and drainage path length in the tests performed with various load velocities, shall be explained primarily with relation to obtained variety of pore pressure dissipation patterns.

The soil structures considered in the analysed tests are natural and modeled (pastes). The distinction between the role of soil structure versus other factors in the deformation characteristics is a research task of itself (Szczepański, 2007). One of the approaches to asses it, is the use of intrinsic soil parameters and normalized parameter - porosity index $I_{V}$ (Szczepański, 2009). This analysis is out of scope of this paper.

The differences in deformation depending on the length of drainage path are more visible in samples of undisturbed structure and less visible in pastes. The shape of $\sigma-\varepsilon$ graphs depends also on pore pressure dissipation (Fig. 4). 


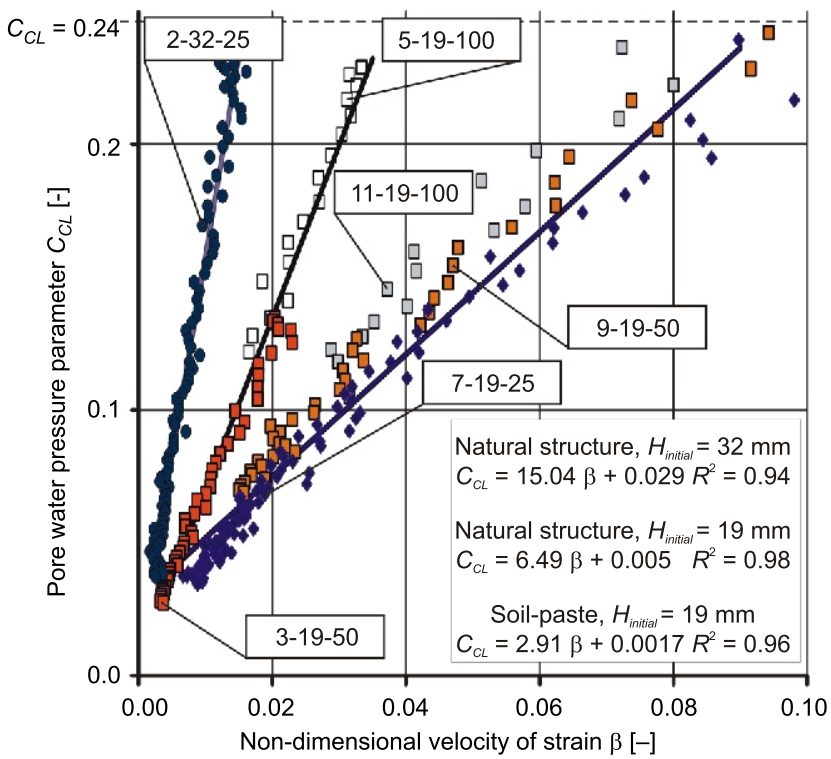

Fig. 5. Specific dependence between non-dimensional velocity of strain $\beta$ vs pore pressure parameter $C_{C L}$ at different conditions of loading velocity, structure and length of drainage

\section{RELATION BETWEEN CONSOLIDATION PROCESS ADVANCING AND} NON-DIMENSIONAL DEFORMATION RATE

The experimental data reveal specific linear dependencies between $C_{C L}$ and b parameters.

Very good linear dependence (Fig. 5) was obtained for the performed paste tests in the ranges of $\beta \in(0,0.25)$ and $C_{C L} \in$ $(0,0.5)$. Criterion of reliability $\beta<0.1$, assumed by Lee et al. (1993), correlates very well in pastes with steady phase $\left(C_{C L}<\right.$ 0.24). Enlargement of the reliability range proposed by Almeida

A NATURAL STRUCTURE

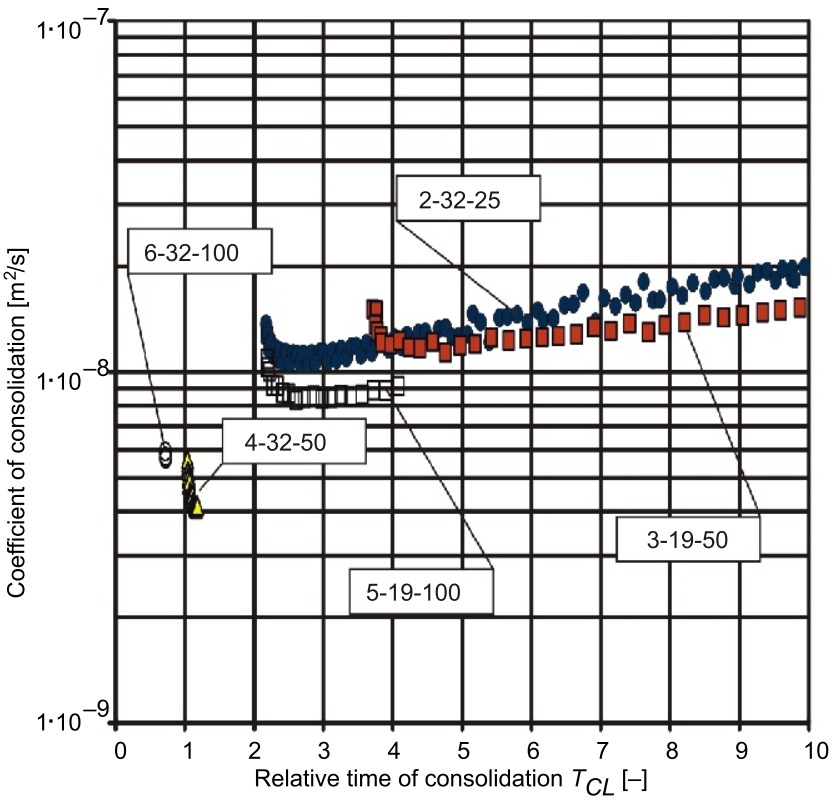

et al. (1995) to $\beta<0.28$ exceeds the steady phase, though for pastes, the quasi rectilinear character of $C_{C L}-\beta$ dependence is preserved.

In the undisturbed structure samples, the $C_{C L}$ increases faster in function $\beta$. Simultaneously, it was noted that the line inclination $C_{C L}=f(\beta)$ is greater for the tests with lengthened drainage path.

Whereas, the analysed linearity does not occur in the unsteady phase for all undisturbed structure soils and pastes, when $C_{C L}>0.24$.

Therefore, the obtained values illustrate correlation areas of test speed criteria, as well as situations, for which only one criterion is accomplished. Faster increase of water pressure parameter $C_{C L}$ in $\beta$ function, observed in case of undisturbed structure samples and lengthened filtration path, points to the necessity to describe individual criteria for determination of allowable $\beta$ value, depending on the soil type and structure.

\section{DISCUSION AND INTERPRETATION OF RESULTS}

\section{COEFFICIENT OF CONSOLIDATION}

Values of $c_{v}$ in pastes are around 0.5 magnitude order lower than for undisturbed structure soils (Fig. 6). It confirms the significance of structural factors. Properties of pastes better correspond to theoretical assumptions taken for the creation of consolidation theory. Diverse filtration resistance in undisturbed structure soils causes discrepancies in the process progress with relation to model solutions. It is reflected in the changeability of the obtained results.

\section{PERMEABILITY COEFFICIENT}

Values of permeability coefficient are calculated indirectly from CL tests, on the basis of the formula:

B SOIL-PASTE

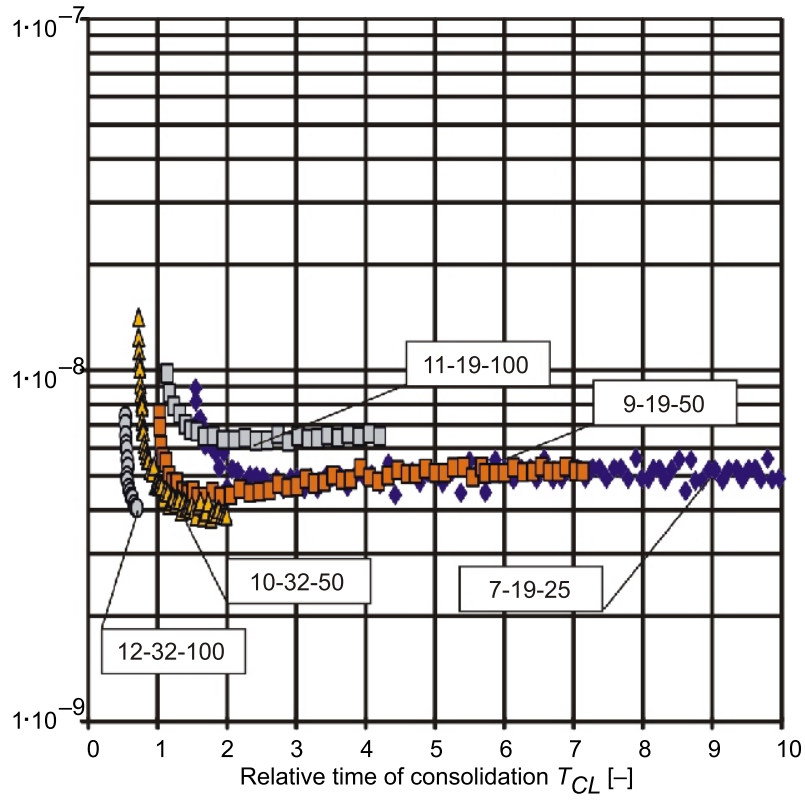

Fig. 6. Coefficient of consolidation $c_{v}$ estimated at different conditions of loading velocity, structure and length of drainage (A - natural structure, B - soil-paste) 
A

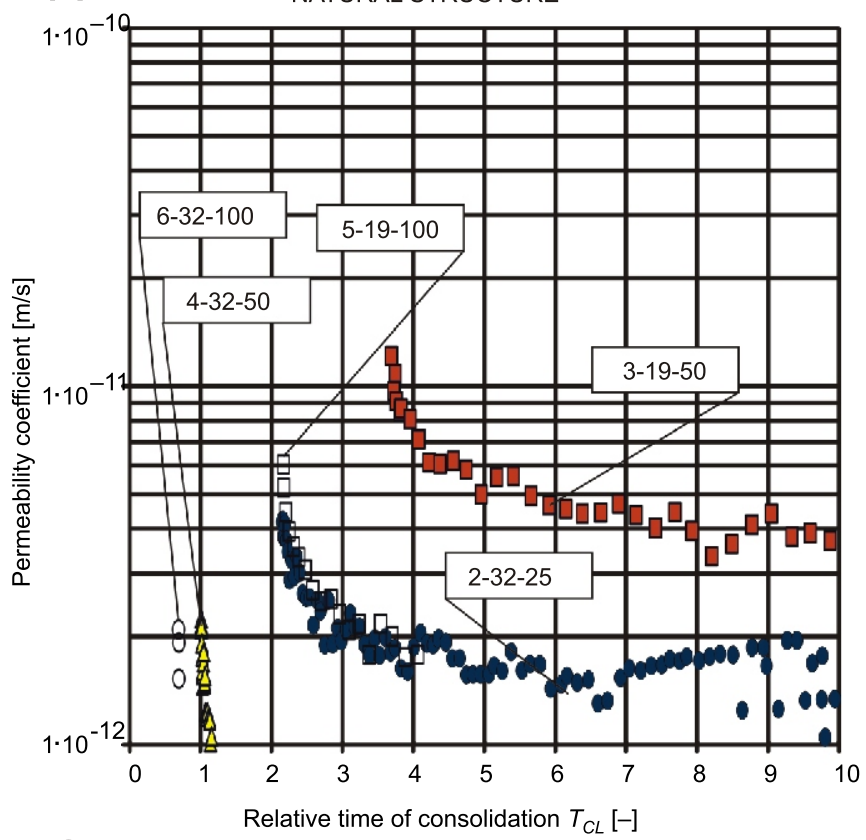

C

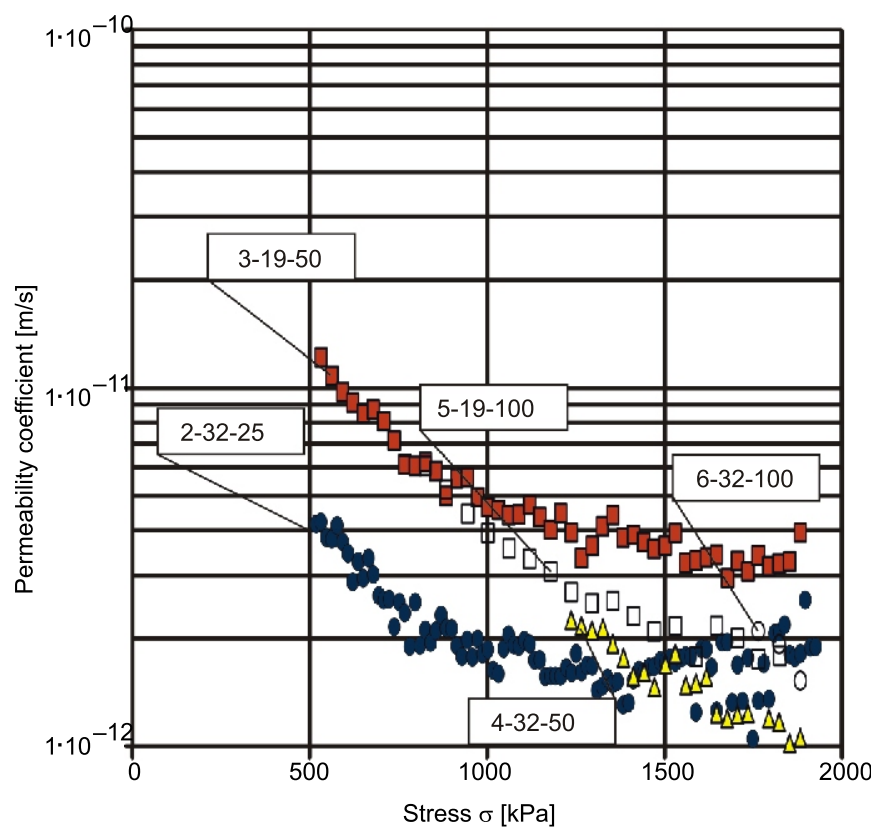

B

SOIL-PASTE

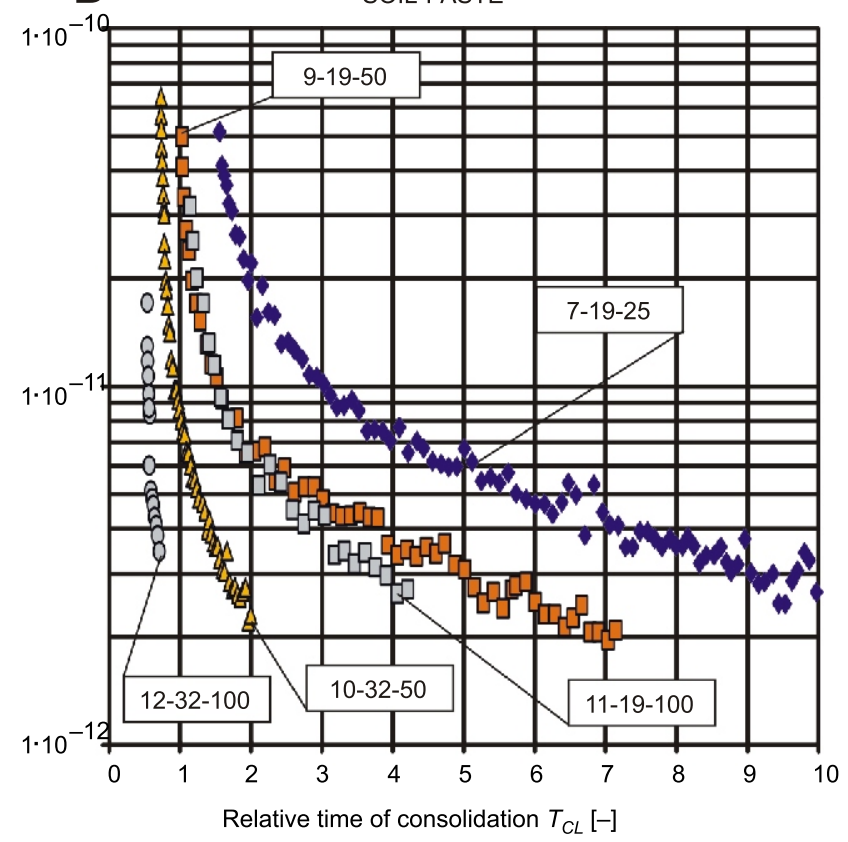

$\mathrm{D}$

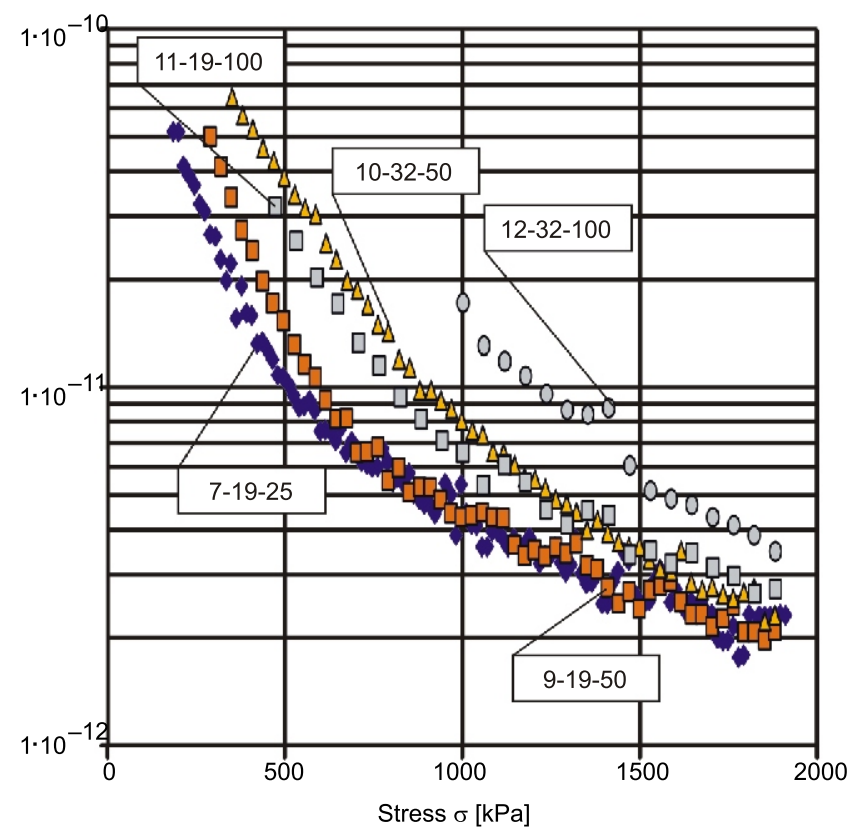

Fig. 7. Permeability alternatively considered on the background of relative time of consolidation (A - natural structure, B - soil-paste) and stress (C - natural structure, D - soil-paste)

$$
k=\frac{c_{v} \cdot \gamma_{w}}{M_{0}}
$$

where: $\gamma_{w}$ - unit weight of water $\left[\mathrm{kN} / \mathrm{m}^{3}\right], M_{0}$ - the modulus of compressibility [kPa], other explanations as in equation [2].

As for pastes, the relations between $k$ values determined under conditions of various load velocities and drainage path lengths, analysed on the basis of stress, are ordered inversely than in analyses led with relation to stress and $T_{C L}$ parameter (Fig. 7).

Analysis of $k$ value changes, performed on the basis of process advancing ( $T_{C L}$ parameter), reveals that values of filtration coefficient decrease in relation to limitation of pore space per- meability. Physically, it results from both decrease of porosity along with deformation progress, as well as from flow contraction under presence of higher pore pressures, which occur under higher load velocities and longer drainage paths.

\section{TEST SPEED OPTIMIZATION}

Determination of the test speed in the laboratory shall undoubtedly correspond to the load conditions occurring in the soil massif.

The first factor moderating the consolidation time and application of load velocity, can be relations between consolidation time and drainage path length (Dobak, 2003). 


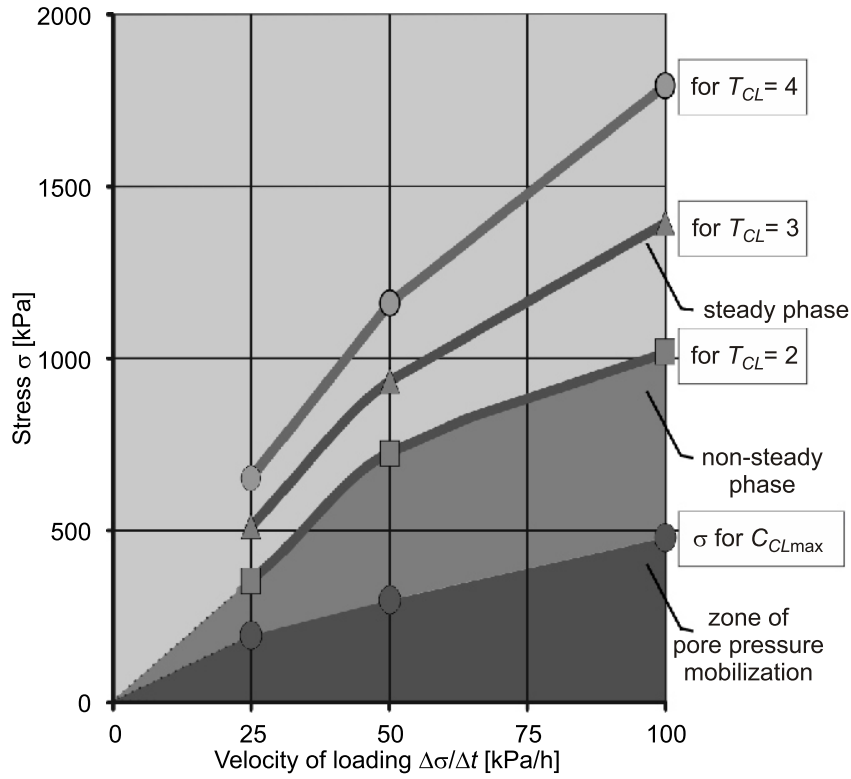

Fig. 8. Reaching the steady phase and appropriate parameters in relation to velocity of loading

$$
\begin{gathered}
\frac{t_{\text {field }}}{t_{\text {lab }}}=\left(\frac{H_{\text {field }}}{H_{\text {lab }}}\right)^{2} \\
\left(\frac{\Delta \sigma}{\Delta t}\right)_{\text {lab }}=\left(\frac{\Delta \sigma}{\Delta t}\right)_{\text {field }} \cdot\left(\frac{H_{\text {field }}}{H_{\text {lab }}}\right)^{2}
\end{gathered}
$$

The second element in laboratory modelling of factors occurring in the soil massif is stress values. Therefore, the test shall enter into the stable phase under stress values corresponding to stress conditions in the massif.

Analysis of correlation between selected parameters of the CL-type consolidation advancing process and load velocities, which have been clearly reflected in the results of soil paste tests, are given in Figure 8.

Analysis of consolidation can be initiated from the moment of reaching pore water pressure maximum value $C_{C L \text { max }}$. Under load velocities 2 and 4 times greater than the initial value of $25 \mathrm{kPa} / \mathrm{h}$, the obtained $C_{C L \max }$ value increased 1.5 and 2.5 times, respectively. The value of stress, under which the test entered into steady phase $\left(T_{C L}=2\right)$, increased 2 and 2.8 times, respectively. Similar characteristics of the value increase were observed under $T_{C L}$ values equal to 2 and 3 .

It is worth noticing that, in the slowest of the examined tests $(\Delta \sigma / \Delta t=24 \mathrm{kPa} / \mathrm{h})$, the stable phase occurred with $\sigma$ values of $300 \mathrm{kPa}$. If the analysis of geological conditions reveals necessity to determine consolidation-filtration parameters under low stress, the programmed load velocity shall be therefore de- creased. On the other hand, under low velocity tests, participation of the filtration factor in the consolidation progress is minor (low $C_{C L \text { max }}$ values), which influences physical conditions of the process and increasing role of rheological factors.

\section{CONCLUSIONS}

As a general conclusion and justification to use the CL approach, it should be emphasized that CL tests allow obtaining much more detailed parameters in a faster way comparing with IL tests.

Consolidation of CL-type (in continuous load mode) has its specific progress, other than the classic model deriving from constant load value (of IL-type).

To determine optimal load velocity in CL-type tests, it is necessary to exploit specific parameters: relative consolidation time $T_{C L}$, pore water pressure parameter $C_{C L}$, as well as their theoretically derived model dependence. The derived model dependence allows separating the test phases, as well as evaluating the consolidation process progress. The CRL test enters into steady phase, when $C_{C L}<0.24$ and $T_{C L}>2$.

The performed analysis of CL-type consolidation progress indicates that determining the mobilization stage of pore pressure, as well as unsteady and steady phases, is crucial for correct interpretation. Reliable results are obtained for steady phase - therefore it is necessary to consider the test progress on the basis of CL-type consolidation maturity.

The applied load velocity significantly influences the pore pressure distribution, as well as the related progress of soil sample axial deformation. In case of higher load values and increased length of drainage path, higher pore pressure values are obtained, as well as phases boundaries are reached later and under higher stress values. Additional analysis not presented herein, is needed to assess the influence of structural factor on deformation characteristics.

Physical conditions of the changes of consolidation and permeability parameters, depending on the applied load velocity, are clearer to analyse with the background consolidation progress, than the stress values themselves.

Non-dimensional parameters: deformation velocity $\beta$ and water pore pressure $C_{C L}$, are the criterion for determination of reliable load velocity in CL tests. Linear relation of these parameters was observed in the range of steady phase. Inclination of the $\beta-C_{C L}$ line depends on structural factors and length of drainage path.

An additional criterion for programming load velocity should be an analysis upon reaching steady phase in relation to stress conditions present in the soil massif.

Acknowledgements. The authors wish to thank to A. Perucho Martinez and the anonymous reviewer for their constructive and useful comments. The research was carried out under the Project N N525 254740 of the Polish National Centre of Science.

\section{REFERENCES}

Aboshi, H., Yoshikumi, H., Maruyama, S., 1970. Constant loading rate consolidation test. Soils and Foundations, 10: 43-56.
Almeida, M.S.S., Martins, I.S., Carvalho, S.R.L., 1995. Constant rate of strain consolidation of Singapore marine clay - discussion to paper: Lee K. et al., 1993. Geotechnique, 45: 333-336. 
Davis, E.H., Raymond, G.P., 1965. A non-linear theory of consolidation. Geotechnique, 15: 161-173.

Dobak, P., 1995. Filtration factor in the consolidation process. Proceedings of XI European on Soil Mechanics and Foundations Division. Kobenhavn: 3.49-3.54.

Dobak, P., 1999. The role of filtration factor in uniaxial consolidation tests of soils (in Polish with English summary). Polish Academy of Sciences, Kraków: 1-225.

Dobak, P., 2003. Loading velocity in consolidation analysis. Geological Quarterly, 47 (1): 13-20.

Dobak, P., 2008. Evaluation of consolidation parameters in $\mathrm{CL}$ tests; theoretical and practical aspects. Geological Quarterly, $\mathbf{5 2}$ (4): 397-410.

Dobak, P., Kowalczyk, S., 2008. Consolidation parameters of Neogene green clays from Bełchatów - a study on CL test interpretation. Geologija, Suplement, 50: 520-525.

Gorman, C.T., Hopkins, T.C., Deen, R.C., Drnevich, V.P., 1978. Constant rate of strain and controlled gradient consolidation testing. Geotechnical Testing Journal, GTJODJ, 1: 3-15.

Kowalczyk, S., 2005. The assessment of pore pressure experimental distributions during continuous loading $(\mathrm{CL})$ consolidation tests (in Polish with English summary). Przegląd Geologiczny, 53: 162-167.

Lee, K., Choa, V., Lee, S.H., Quek, S.H., 1993. Constant rate of strain consolidation of Singapore marine clay. Geotechnique, 43: 471-488.

Lowe, J., Jonas, E., Obricians, V., 1969. Controlled gradient consolidation tests. Journal of the Soil Mechanics and Foundations
Division, Proceedings of the American Society of Civil Engineers, 95: 77-97.

Sallfors, G., 1975. Pre-consolidation pressure of soft highly plastic clays. Chalmers University of Technology, Goteborg.

Smith, R.E., Wahls, H.E., 1969. Consolidation under constant rate of strain. Journal of the Soil Mechanics and Foundations Division, Proceedings of the American Society of Civil Engineers, 95: 519-539.

Szczepański, T., 2007. OCR versus YSR - a discussion of classic and today's views on preconsolidation of clayey soils (in Polish with English summary). Przegląd Geologiczny, 55: 405-410.

Szczepański, T., 2009. Nowa metoda oceny stanu przekonsolidowania gruntów (in Polish). In: Problemy geotechniczne i środowiskowe z uwzględnieniem podłoży ekspansywnych (eds. E. Dembicki, M.K. Kumor and Z. Lechowicz): 447-452. Wydawnictwo Uczelniane UTP.

Terzaghi, K., Peck, R.B., 1967. Soil Mechanics in Engineering Practice. Wiley, New York.

Vu Cao Minh, 1977. New test method of soils consolidation (in Polish with English summary). Archiwum Hydrotechniki, 24: 253-257.

Wissa, A.E.Z., Christian, J.T., Davis, E.H., Heiberg, S., 1971. Consolidation at constant rate of strain. Journal of the Soil Mechanics and Foundations Division, Proceedings of the American Society of Civil Engineers, 97: 1393-1412.

Woźniak, H., 2009. The settlement of dump soils - data from modeling (in Polish with English summary). IGSMiE PAN Kraków. 